\title{
Standardisation of gas mixtures for estimating carbon monoxide transfer factor
}

\author{
A H Kendrick, G Laszlo
}

\begin{abstract}
Background-The American Thoracic Society recommends that the inspired concentration used for the estimation of carbon monoxide transfer factor (TLCO) mixture should be $0 \cdot 25-0.35 \%$ carbon monoxide, 10-14\% helium, 17-21\% oxygen, balance nitrogen. Inspired oxygen influences alveolar oxygen and hence carbon monoxide uptake, such that transfer factor increases by $0.35 \%$ per $\mathrm{mm} \mathrm{Hg}$ decrease in alveolar oxygen. To aid in the standardisation of TLCO either a known inspired oxygen concentration should be used, or Thco should be corrected to a standard inspired oxygen concentration. The range of gas mixtures used in practice and the implications for cost and accuracy have been investigated.
\end{abstract}

Methods-A questionnaire was sent to 185 respiratory units in the UK requesting information on (1) the method used to estimate TLCo, (2) the manufacturer of the equipment, (3) the mixture used, (4) whether "medical quality" gas was ordered, and (5) the level of satisfaction with supplier service.

Results-Replies were received from 106 units. Most used the single breath breath holding method for which 17 different test mixtures were ordered. One unit also used the single breath exhalation method. Inspired oxygen ranged from $17 \cdot 94 \%$ to $25 \%$, giving a wide variation in alveolar oxygen and hence TLCo. Forty seven units ordered a specific inspired oxygen, the rest ordering "air" as balance. The cost per litre of gas varied greatly, with the mixture $14 \%$ helium, $\mathbf{0} \cdot \mathbf{2 8} \%$ carbon monoxide, balance air (17.9\% oxygen) and $10 \%$ helium, $0.28 \%$ carbon monoxide, balance air (18.8\% oxygen) being cheapest to produce. Ordering a specific inspired oxygen concentration increased the cost. Large cylinders of gas were cheaper for the same mixture. The mixture for the exhalation method was the most expensive. Sixty seven units ordered "medical quality" gas and six assumed this was supplied. Twenty nine (27\%) were dissatisfied with their supplier due to (1) poor service, (2) long delivery times, (3) costs, or (4) wrongly labelled cylinders.
Conclusions-It is recommended that two mixtures be available: (a) $14 \%$ helium, $0 \cdot 28 \%$ carbon monoxide, balance air for a helium analyser reading up to $15 \%$, and (b) $10 \%$ helium, $0.28 \%$ carbon monoxide, balance air for lower reading helium analysers. The mixture should be produced under a medical product licence. The advantage of the single exhalation method for routine clinical use needs to be investigated in view of the higher cost of the mixture.

(Thorax 1993;48:863-865)

The standard gas mixture for the estimation of carbon monoxide transfer factor (TLCO) by the single breath breath holding method contains a small quantity of carbon monoxide, the inert gas helium, and a balance of oxygen and nitrogen. In its recent guidelines the American Thoracic Society ${ }^{1}$ recommended that the magnitude of each component should be $0.25-0.35 \%$ carbon monoxide, $10-14 \%$ helium, 17-21\% oxygen, balance nitrogen. Of particular importance is the concentration of inspired oxygen $\left(\mathrm{FIO}_{2}\right)$ since this in turn influences the alveolar oxygen $\left(\mathrm{PAO}_{2}\right)$ and hence the uptake of carbon monoxide across the alveolar-capillary membrane. Kanner and Crapo $^{2}$ have shown that TLCo increases by $0.35 \%$ per $\mathrm{mm} \mathrm{Hg}$ decrease in $\mathrm{PAO}_{2}$. It is therefore important that the $\mathrm{FIO}_{2}$ is standardised to a single level, which in Europe is currently recommended as $0 \cdot 18$. $^{3}$

In addition to standardising for $\mathrm{FIO}_{2}$ there are potentially significant financial implications of using different combinations of carbon monoxide, helium, oxygen and nitrogen to measure TLCO, and potential legal implications of using gas mixtures which are not covered by a medical product licence.

The purpose of this study was to determine (1) the different mixtures ordered by departments, (2) whether the mixtures were ordered with a medical product licence, and (3) the level of satisfaction with supplier service.

\section{Methods}

QUESTIONNAIRE

A questionnaire was sent to 185 respiratory units in the UK, requesting information on (1) the method principally used to estimate TLCO (2) the manufacturer of the equipment, 
(3) the precise mixture ordered from the supplier, (4) whether this was ordered as "medical quality", and (5) any problems the laboratory had with the supplier.

\section{ANALYSIS}

The potential costs of the different gas mixtures were assessed by obtaining price quotations from a single supplier (British Oxygen Company) for some of the mixtures used and calculating the cost in pence per litre. This included the cost of the certificate of analysis, but not delivery or rental charges. The least expensive analysis was selected (certified) giving a tolerance of between $\pm 2 \%$ and $\pm 5 \%$ of each component. An estimate of the yearly expenditure was based on a throughput of six patients per day, each requiring six litres of inspired gas plus one litre per day for calibration of the gas analysers for one year of 250 working days.

\section{Results}

Replies were received from 106 laboratories. Of these 103 routinely performed the single breath breath hold measurement, two performed steady state measurements, and one rebreathing measurements. One laboratory also performed the single breath exhalation method. The majority of laboratories $(77 \%)$ used equipment from PK Morgan Ltd, the remainder using either Jaeger $(10 \%)$ or Gould/Sensormedics equipment (12\%).

\section{MIXTURES}

Seventeen gas mixtures were ordered for the breath hold method of which 12 were for the Morgan equipment (table). One mixture was

\begin{tabular}{|c|c|c|c|}
\hline Number & $\begin{array}{l}\text { Helium } \\
(\%)\end{array}$ & $\begin{array}{l}\text { Carbon } \\
\text { monoxide } \\
(\%)\end{array}$ & Balance \\
\hline \multicolumn{4}{|c|}{ Morgan mixtures: } \\
\hline 1 & $14 \cdot 0$ & $0 \cdot 30$ & Air \\
\hline 2 & $14 \cdot 0$ & $0 \cdot 28$ & Air \\
\hline 3 & $14 \cdot 0$ & 0.28 & $18 \%$ oxygen/nitrogen \\
\hline 4 & $14 \cdot 0$ & 0.29 & $18 \%$ oxygen/nitrogen \\
\hline 5 & $14 \cdot 0$ & $0 \cdot 30$ & $18 \%$ oxygen/nitrogen \\
\hline 6 & $15 \cdot 0$ & $0 \cdot 30$ & Air \\
\hline 7 & $14 \cdot 4$ & $0 \cdot 28$ & $18 \%$ oxygen/nitrogen \\
\hline 8 & $14 \cdot 0$ & $0 \cdot 28$ & $20 \%$ oxygen/nitrogen \\
\hline 9 & $16 \cdot 0$ & $0 \cdot 30$ & $21 \%$ oxygen/nitrogen \\
\hline 10 & $13 \cdot 6$ & $0 \cdot 29$ & Air \\
\hline 11 & $15 \cdot 0$ & 0.30 & $25 \%$ oxygen/nitrogen \\
\hline 12 & $15 \cdot 0$ & 0.30 & $20 \%$ oxygen/nitrogen \\
\hline \multicolumn{4}{|c|}{ Jaeger/Inmed mixtures: } \\
\hline 13 & $9 \cdot 0$ & $0 \cdot 28$ & Air \\
\hline 14 & $10 \cdot 0$ & $0 \cdot 30$ & $21 \%$ oxygen/nitrogen \\
\hline 15 & $10 \cdot 0$ & 0.30 & Air \\
\hline 16 & $9 \cdot 5$ & $0 \cdot 28$ & Air \\
\hline 17 & $10 \cdot 0$ & 0.30 & $18 \%$ oxygen/nitrogen \\
\hline \multicolumn{4}{|c|}{ Exhalation mixture ${ }^{\star}$} \\
\hline \multicolumn{4}{|c|}{$\begin{array}{l}0.30 \% \text { carbon monoxide } \\
0.30 \% \text { methane } \\
0 \cdot 30 \% \text { acetylene } \\
21 \cdot 0 \% \text { oxygen } \\
\text { Balance nitrogen }\end{array}$} \\
\hline
\end{tabular}

*Allows simultaneous estimation of pulmonary blood flow using acetylene. The methane replaces helium as the inert gas. ordered for the exhalation method. There were small differences in the carbon monoxide concentrations and the helium concentrations were dependent on the manufacturers' analysers. The oxygen concentrations ranged from $17.94 \%$ to $25 \%$. Forty seven units $(44 \%)$ requested a specific oxygen concentration, the remainder requesting the balance as "air". Sixty seven laboratories (63\%) ordered "medical quality" mixtures, with a further six assuming that they were supplied with this standard of mixture. Twenty nine laboratories $(27 \%)$ were dissatisfied with their supplier due to (a) poor service, (b) long delivery times, (c) cost of mixtures and delivery charges, or (d) wrongly labelled cylinders.

\section{costs}

Quotations were obtained for 12 of the mixtures at three different gas quantities (fig). The cost per litre of gas was dependent on the quantity of gas ordered and on the analysed components of the mixture. Generally, the more components that required analysis, the greater the cost. The cheapest mixture was mixture 2 , while the most expensive was for the slow exhalation (mixture 18). The costs per year ranged from $£ 99.90$ for mixture 2 to $£ 225.70$ for mixtures 3, 11 and 12 for a 6380 litre cylinder, and from $£ 449.55$ to $£ 1019 \cdot 35$ for the same mixtures when using a 1270 litre cylinder. The slow exhalation mixture would cost between $£ 283.98$ and $£ 1284 \cdot 83$, depending on the cylinder size.

\section{Discussion}

The gas mixtures used to estimate TLCO showed a wide variation in the magnitude of their components and hence in their cost per litre. The accuracy of the quoted mixtures was not verified, and small differences will occur between suppliers. Since most laboratories performed the single breath breath hold measurement, the cost of the gas per litre should only be determined by two factors. Firstly, equipment sold by PK Morgan employs a helium analyser which is capable of measuring helium to about $15 \%$, whereas the helium analysers used by Jaeger, Chest and Inmed (marketing Gould/Sensormedics equipment) are capable of measuring up to $10 \%$ helium. At most there is therefore a need for two mixtures with the same concentration of carbon monoxide and either $10 \%$ or $14 \%$ helium. In theory only one gas mixture needs to be used, and since all analysers are capable of measuring up to $10 \%$ helium, this would be the mixture of choice. However, the PK Morgan analyser has better linearity and resolution over its upper range, and for this instrument the $14 \%$ helium mixture is more appropriate (PK Morgan, personal communication). Secondly, the volume of gas ordered affects cost. Small cylinders are easier to handle and potentially pose less of a safety hazard than the much larger cylinders. The larger the volume of gas purchased, however, the cheaper the cost per litre. The 


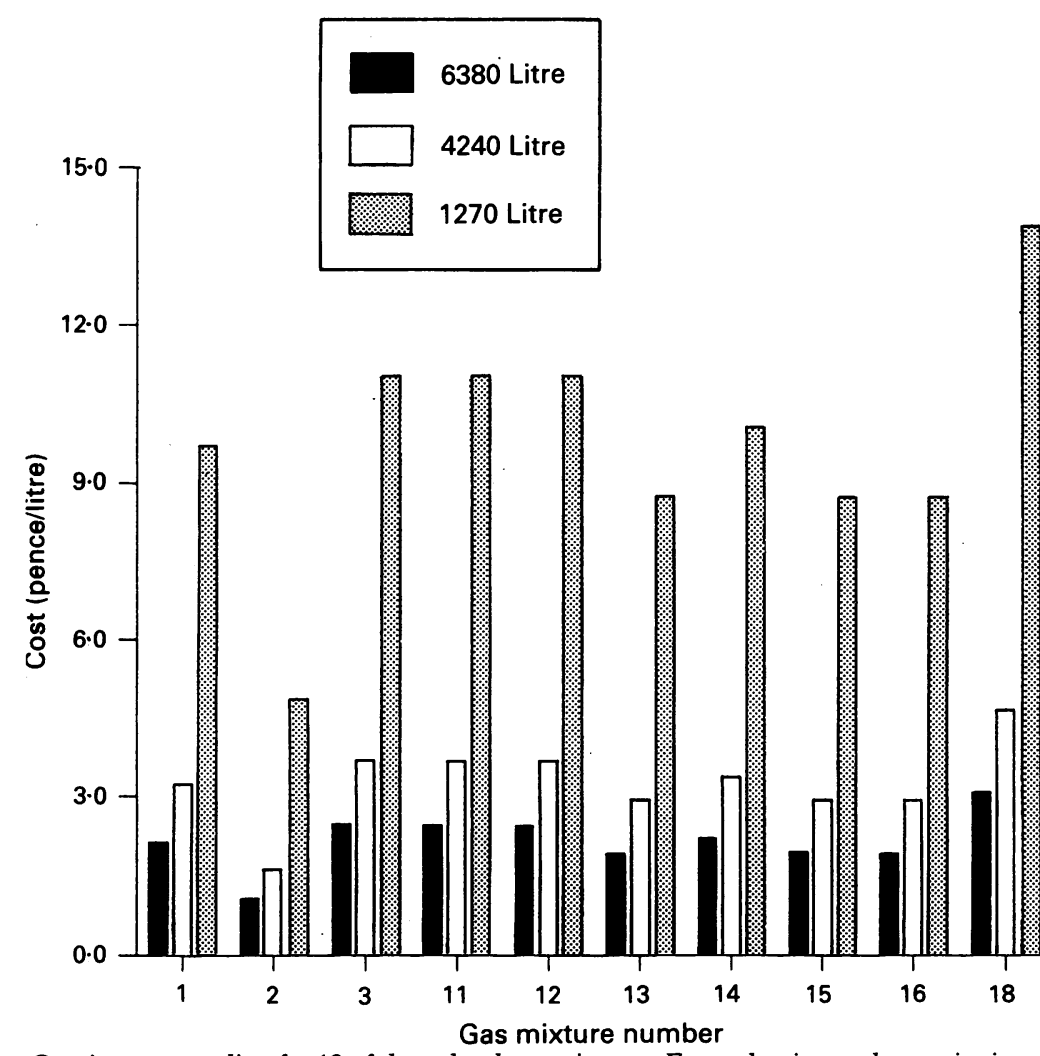

Cost in pence per litre for 12 of the ordered gas mixtures. For each mixture the cost is given dependent on the volume of gas ordered: 6380, 4240, or 1270 litres. The numbers along the $x$ axis refer to the mixtures in the table.

cost of delivery varies between suppliers, and therefore purchasers should ensure that these costs are included when deciding on supplier.

\section{OXYGEN CONCENTRATION}

One major variant was the oxygen concentration used by laboratories. This ranged from $17 \cdot 94 \%$ to $25 \%$, with a number of laboratories specifically stating a required oxygen concentration. If an oxygen concentration is specifically requested, the supplier will attempt to supply that mixture. As this is a third component that requires analysis, the cost of the mixture will consequently increase regardless of the volume of gas ordered (fig). Transfer factor is dependent on the inspired and hence alveolar oxygen concentration, so a higher inspired oxygen concentration such as $25 \%$ will result in a TLCO which is lower than if the inspired concentration was $17 \%$. As a rough approximation, an inspired oxygen concentration of $25 \%$ would give an alveolar oxygen concentration of about $22 \%(157 \mathrm{~mm}$ $\mathrm{Hg}$ ), while an inspired concentration of $18 \%$ would give an alveolar concentration of about $15 \%(107 \mathrm{~mm} \mathrm{Hg})$ at the end of a breath hold. The approximate difference in TLCO would be $15.5 \% .^{2}$

This magnitude of variation can be considerably reduced if the balance requested is in "air". The concentration of oxygen in a mixture containing $0.28 \%$ carbon monoxide, $14 \%$ helium in air, would be $17.9 \%$, which is close to that recommended by the European standard of $18 \%$. For a mixture of $0.28 \%$ carbon monoxide, $10 \%$ helium in air the oxygen concentration would be $18 \cdot 8 \%$. This small difference in the inspired oxygen concentration would introduce an error in the estimate of TLCO of only about $2 \%$ between laboratories which could be eradicated if all helium analysers employed the higher range.

\section{MEDICAL QUALITY GASES}

Gas mixtures that are produced under a product licence have been made under strict conditions and in accordance with Good Manufacturing Practice. ${ }^{4}$ All sites for the production are subject to licensing and inspection by the Medicines Control Agency. Where a gas has been produced under a product licence liability for its use, in terms of safety and efficacy, remain with the manufacturer providing the mixture is used in accordance with the terms of the licence. If a mixture is found to be defective and causes injury the manufacturer may be strictly liable under the Consumer Protection Act of 1987. It is not a legal requirement that TLCO mixtures to be used on patients should have a medical product licence, but the departmental good practice policy should indicate the need for such a licence.

\section{SLOW EXHALATION METHOD}

This elegant method of measuring transfer factor, ${ }^{5}$ combined with pulmonary blood flow, provides potentially useful information on the gas exchange process of the lungs. The mixture as ordered employs acetylene to estimate blood flow and replaces helium with methane. This allows the gases to be analysed using a single infrared analyser. The cost of this mixture is higher than the single breath method, and as yet there are no published data regarding the clinical usefulness of this technique.

\section{RECOMMENDATIONS}

To improve standardisation of TLCO, reduce costs, and achieve good practice it is recommended that for the moment two mixtures should be available (a) $14 \%$ helium, $0.28 \%$ carbon monoxide, balance air for Morgan equipment, and (b) $10 \%$ helium, $0.28 \%$ carbon monoxide, balance air for Jaeger/Inmed equipment. The mixtures should be produced under a medical product licence and all manufacturers should in future supply linear helium analysers capable of reading up to $15 \%$. The single exhalation method needs to be evaluated.

Our thanks to the laboratories who replied to the questionnaire; to Nigel Wadsworth of British Oxygen Company for quotations of the various gas mixtures; and to Dr PD Harrowing, Quality Manager, Pharmacy Unit, Bristol Royal Infirmary for advice on medical product licences.

1 American Thoracic Society. Single breath carbon monoxide diffusing capacity (transfer factor). Recommendations for a standard technique. Am Rev Respir Dis 1987;136:1299-307.

2 Kanner RE, Crapo RO. The relationship between alveolar oxygen tension and the single-breath carbon monoxide diffusing capacity. Am Rev Respir Dis 1986;133:676-8.

3 Quanjer PhH. Standardized lung function testing. Bull Eur Physiopathol Respir 1983;19(Suppl 5):41.

4 Scawin JH. Gas mixtures for CO transfer factor: production and quality control. Breath 1989;37:5-6.

5 Newth CJL, Cotton DJ, Nadel JA. Pulmonary diffusing capacity measured at multiple intervals during a single exhalation in man. 7 Appl Physiol 1977;43:617-25. 